Review Article

\title{
The Evolution of Dendritic Cell Immunotherapy against HIV-1 Infection: Improvements and Outlook
}

\author{
Hager Mohamed, Vandana Miller $\mathbb{D}^{\mathbb{Q}}$, Stephen R. Jennings, Brian Wigdahl, \\ and Fred C. Krebs
}

Department of Microbiology and Immunology, Center for Molecular Virology and Translational Neuroscience, Institute for Molecular Medicine and Infectious Disease, Drexel University College of Medicine, Philadelphia, PA 19102, USA

Correspondence should be addressed to Fred C. Krebs; fkrebs@drexelmed.edu

Received 20 February 2020; Accepted 28 April 2020; Published 25 May 2020

Academic Editor: Ravirajsinh Jadeja

Copyright (C) 2020 Hager Mohamed et al. This is an open access article distributed under the Creative Commons Attribution License, which permits unrestricted use, distribution, and reproduction in any medium, provided the original work is properly cited.

\begin{abstract}
Dendritic cells (DC) are key phagocytic cells that play crucial roles in both the innate and adaptive immune responses against the human immunodeficiency virus type 1 (HIV-1). By processing and presenting pathogen-derived antigens, dendritic cells initiate a directed response against infected cells. They activate the adaptive immune system upon recognition of pathogen-associated molecular patterns (PAMPs) on infected cells. During the course of HIV-1 infection, a successful adaptive (cytotoxic CD8 ${ }^{+} \mathrm{T}^{-}$ cell) response is necessary for preventing the progression and spread of infection in a variety of cells. Dendritic cells have thus been recognized as a valuable tool in the development of immunotherapeutic approaches and vaccines effective against HIV-1. The advancements in dendritic cell vaccines in cancers have paved the way for applications of this form of immunotherapy to HIV-1 infection. Clinical trials with patients infected with HIV-1 who are well-suppressed by antiretroviral therapy (ART) were recently performed to assess the efficacy of DC vaccines, with the goal of mounting an HIV-1 antigen-specific T-cell response, ideally to clear infection and eliminate the need for long-term ART. This review summarizes and compares methods and efficacies of a number of DC vaccine trials utilizing autologous dendritic cells loaded with HIV-1 antigens. The potential for advancement and novel strategies of improving efficacy of this type of immunotherapy is also discussed.
\end{abstract}

\section{Introduction}

Despite the demonstrated efficacy of combination antiretroviral therapy (ART), treatment of infection by the human immunodeficiency virus type 1 (HIV-1) still necessitates life-long use of ART to effectively suppress viremia in infected patients. This is partly attributed to ineffective HIV-1-specific cell-mediated immune responses due to impaired dendritic cell function in many patients on ART. Interestingly, a small percentage of infected individuals are termed "elite controllers" for their ability to control HIV-1 replication without ART. The protection from disease progression in these individuals has been attributed to robust HIV-1-specific antigen presentation and a $\mathrm{CD} 8^{+}$cytotoxic Tlymphocyte (CTL) response targeted against HIV-1 [1, 2]. Dendritic cell immunotherapy might have the capacity to control HIV-1 infection in the absence of ART, similar to the ability of elite controllers to do so. This type of immunotherapy involves loading dendritic cells (DCs) with antigens ex vivo then introducing the cells back into the patient. This approach has been investigated as a treatment for patients with pancreatic cancer or melanoma [3-5].

Dendritic cells have been shown to be critical to the recognition of HIV-1, regulation of T-cell function, and targeting of infected cells by activation of the adaptive immune system through presentation of HIV-1 antigens [6, 7]. The versatility of DCs in contrast with other antigen-presenting cells has been attributed to the presentation of antigens on both major histocompatibility complex (MHC) class I and MHC II molecules. Unlike other immune cells that primarily activate $\mathrm{CD}^{+} \mathrm{T}$ helper cells via MHC class II, DCs have the ability to process and cross-present HIV-1 antigens from dying cells and display them on MHC class I molecules to activate cytotoxic $\mathrm{CD} 8^{+} \mathrm{T}$-lymphocytes [8-11]. In chronic 
HIV-1 infection, dendritic cells have been shown to be greatly reduced in number and shown to be inefficient antigen presenters [12-15]. In addition, predicting DC function is particularly difficult in the course of the disease in the elderly population [16]. While it may not be possible to enhance DC numbers, enhancement of antigen capture and presentation may be beneficial for the control of the highly variant HIV-1 population from patient to patient.

A personalized immunotherapy approach for the treatment of HIV-1 infection has thus been the aim of many recent studies, which have focused on helping the patient's own immune response better target and clear HIV-1infected cells. To this end, clinical trials using autologous dendritic cell-based vaccines have been conducted. Similar to cancer, HIV-1 infection progresses via evasion of immune system recognition. In addition, HIV-1 in particular has been shown to compromise the immune system by exhausting Tcells. In this regard, DC immunotherapy has been focused on enhancing the induction of CTL responses [17].

The immunotherapy approach is unlike other methods of vaccination, which is aimed at eliciting broadly neutralizing antibodies usually directed against the HIV-1 structural Env protein. Accordingly, broadly neutralizing antibodies targeting regions of the HIV-1 envelope such as the V1/V2 loop, gp120 glycan residues, and the CD4 binding site have failed due to mutations that result in "escape" viruses [1820]. A DC immunotherapy approach intended to control viral replication and disease progression, however, does not depend entirely on the neutralization of free virions. The added advantage of this approach is that it has allowed various methods of ex vivo manipulation, such as coculture systems using patient DCs with T-cells. The goal of this form of immunotherapy has been to establish a sustained T-cell response against HIV-1 in infected patients, ideally without the concern for viral rebound. In this review, the design as well as the results obtained from a number of recent clinical trials involving the use of HIV-1-specific DC vaccines will be discussed to give insights with respect to the potential of this immunotherapy approach to provide a practical tool for HIV-1 treatment.

\section{Methods for Designing HIV-1 Antigen- Loaded Dendritic Cells Ex Vivo}

DC-based immunotherapy approaches, of course, rely on the ability to produce and manipulate dendritic cells ex vivo through the use of some well-characterized methods. Past studies have differed in the antigen choice and techniques used for delivering antigen to DCs. Studies involving DCs commonly use monocyte-derived dendritic cells obtained from HIV-1-infected patients using leukapheresis [21-23]. Monocytes are obtained from peripheral blood mononuclear cells (PBMC) and then induced to mature in vitro through culturing with cytokines such as granulocyte-macrophage colony-stimulating factor (GM-CSF) (Figure 1). During priming in vivo, GM-CSF is released by cytotoxic T-cells as a dendritic cell licensing factor, which has been shown to promote the expression of costimulatory molecules [24, 25]. Other cytokines may also be used for stimulating maturation, including interleukin-1 $\beta$ (IL-1 $\beta$ ), IL-4, IL-6, tumor necrosis factor- $\alpha$ (TNF- $\alpha$ ), and the interferons IFN- $\alpha$ and IFN- $\gamma$ $[12,21-23,26]$. Ex vivo manipulation of DCs has the advantage of favoring a desired outcome while avoiding off target effects that may occur in vivo, since many cytokines function in vivo in feedback loops that promote opposing effects, including up- and downregulation of HIV-1 gene expression [27].

2.1. Choice of HIV-1 Antigens. As research has progressed into utilizing DC vaccines for HIV-1 immunotherapy, antigen loading has become an important concern. The use of HIV-1 mRNA for DC loading has become very common. Autologous antigens have in some cases been favored against general consensus sequences or synthetic antigens. Moreover, antigen combinations have become preferred by most studies over single antigens in order to address concerns of poor long-term viral suppression and lack of immunogenicity.

Dendritic cell immunotherapy approaches for HIV-1 infection have encompassed the use of both structural and nonstructural HIV-1 proteins. Structural and enzymatic proteins strictly required at specific points in the HIV-1 replication cycle are encoded by the gag, pol, and env genes [28, 29]. The regulatory proteins Tat and Rev, which are encoded by rev and tat, respectively [30-32], are similarly required for productive replication. The vif, $v p r$, nef, and $v p u$ genes encode accessory proteins that are, in contrast, not strictly required, as shown in numerous in vitro systems. The inclusion of accessory proteins in vaccine design efforts partially stems from growing knowledge of their critical roles in the progression of HIV-1-associated disease despite not being strictly required during viral replication in vitro $[33,34]$.

Antigens can come from individual patients (autologous antigens) or derived synthetically from consensus HIV-1 sequences that can be found across large numbers of patients. For example, three synthetic peptides were designed based on consensus amino acid sequences at residues 386-394 in Gag, 498-506 in Pol, and 134-142 in Env [21]. Induction of T-cell responses has indeed been observed to conserved Gag sequences loaded onto dendritic cells in vitro in both HIV1-infected and HIV-1-uninfected cells [35]. While the use of consensus sequences appears more convenient, it has also been associated with a lack of specific $\mathrm{CD} 8^{+} \mathrm{T}$-cells elicited against patient-specific viral strains in failed clinical trials. More recent studies thus instead have investigated the use of patient-derived HIV-1 antigens and autologous Gag and accessory proteins Nef, Rev, and Vpr [35-38]. The use of HIV-1 mRNA encoding the Tat and Vpx proteins has also been studied [39, 40]. A combination of structural and nonstructural HIV-1 antigens can also be accommodated, further allowing more options for the reliance on conserved regions in each protein to target and limit variations in clinical outcomes [41]. In addition to creating a more "personalized" approach, the use of autologous antigens (Figure 1) has the benefit of allowing extraction of HIV-1 RNA from latently infected $\mathrm{CD}^{+}$T-lymphocytes that could not be cleared by ART [42].

2.2. Viral versus Nonviral Methods for Delivering Antigen to DCs. HIV-1 RNA has been introduced into dendritic cells 


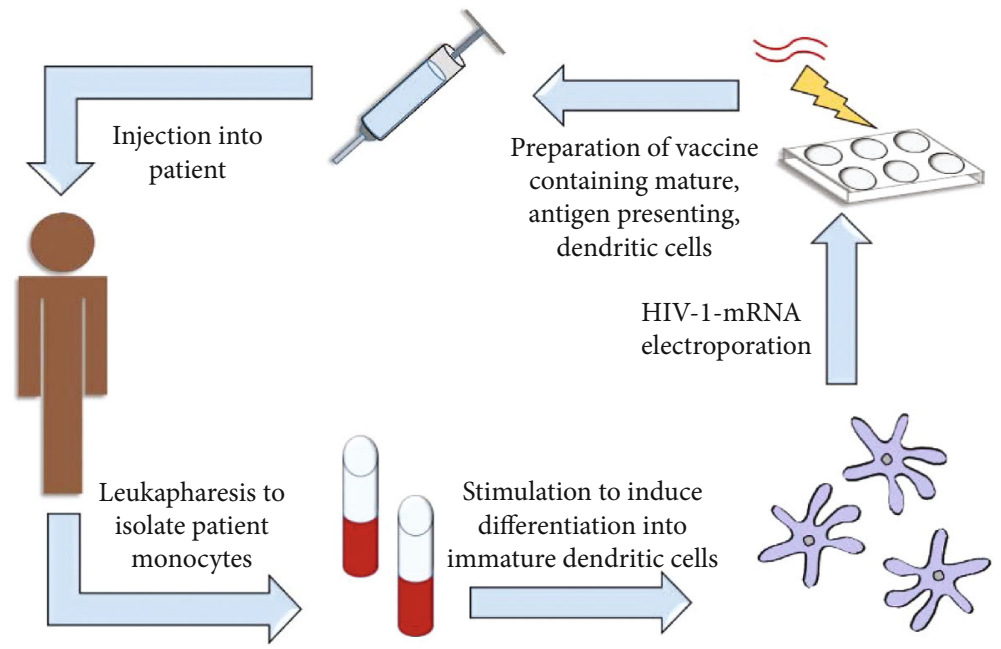

FIGURE 1: Autologous dendritic cell vaccines are prepared using the patient's own monocytes from PBMCs obtained through leukapheresis. The monocytes are stimulated in vitro with growth cytokines to induce differentiation into immature dendritic cells. The dendritic cells may then be loaded with HIV-1-derived antigen, commonly introduced via mRNA electroporation, after which they will become mature, antigenpresenting dendritic cells. They can then be formulated into a vaccine that is administered to the patient to elicit a T-cell response specific to the HIV-1 antigen and evoke an enhanced response against HIV-1-infected cells.

by nonviral and viral delivery methods utilizing different vectors. Delivery methods include the commonly used electroporation as well as viral vectors such as adenovirus and poxviruses [35, 39, 43-45]. In a recent study, dendritic cells were transduced with a lentiviral vector containing $\mathrm{Vpx}$ and were shown to induce multiple proinflammatory cytokines as well as an antigen-specific CTL response with donor cells in vitro [40]. The induction of an array of proinflammatory cytokines and chemokines was also demonstrated when DCs were transduced with the modified Vaccinia Vaccine Ankara (MVA) poxvirus vector, which has been used to simultaneously induce the maturation of monocyte-derived dendritic cells upon infection, marked by an increase in cell surface CD86 and HLA-DR expression [44]. More DC immunotherapy experiments utilizing viral vectors for in vivo delivery of HIV-1 RNA are necessary help to clarify their safety profiles in HIV-1 patients. Nonetheless, the HIV-1 antigen choice and loading in clinical trials over the years have shifted to HIV-1 mRNA electroporation as opposed to loading peptides, inactivated viruses, or whole cells (Figure 2). This technique, which introduces nucleic acids into the cell by transiently disrupting the cell membrane with short, high-voltage pulses, can achieve a greater than $90 \%$ transfection efficiency [46-49]. The incorporation of additional molecules used simultaneously with HIV-1 antigens in the DC vaccine design to enhance DC function has also emerged in these trials [21,38,50-52]. This includes the coelectroporation of DCs with RNA encoding the CD40 ligand $(\mathrm{CD} 40 \mathrm{~L})$ to enhance the maturation and antigen presentation of DCs [38] (Figure 2).

2.3. Insights from DC Coculture Analysis. Following antigen introduction, manipulation of DCs in in vitro co-culture systems has facilitated the ability of the engineered DCs to induce T-cell activation and proliferation, giving insights into the immunogenicity of antigens that were used and the nature of presentation to the T-cells $[35,44,58]$. A coculture of MVA-infected dendritic cells within a mixed lymphocyte culture demonstrated cellular activation and an increase in IFN- $\gamma$ production in both $\mathrm{CD}^{+}$and $\mathrm{CD} 8^{+} \mathrm{T}$-lymphocytes. The ability of dendritic cells to induce proliferation and differentiation of Th1 cells has been observed [44]. Assessment of an effector versus memory T-lymphocyte response as a result of HIV-1 RNA introduction to dendritic cells has also been made possible. Autologous Gag-transfected dendritic cells were found to induce an increase in central memory $\mathrm{CD}^{+} \mathrm{T}$-cells in a coculture with patient T-lymphocytes, as shown by detection of markers associated with various $\mathrm{T}$ lymphocyte populations following coculture for 12 days [35]. Coculture experiments thus enable early assessment of T-lymphocyte differentiation under a variety of conditions in response to DCs manipulated ex vivo.

\section{Variables and Therapeutic Outcomes of Clinical Trials}

Many HIV-1 dendritic cell vaccines that have shown promise in vitro have reached clinical trials in which efficacy was investigated in patients with well-suppressed HIV-1 infections. The efficacy of immunotherapy can be expected to be dependent on numerous factors, including host genetics, whether patients remain on ART or discontinue ART after treatment, the necessary frequency of administration, the site of inoculation, and the severity of their immunocompromised state before initiating immunotherapy. An additional challenge in clinical trials of DC immunotherapy has been the genetic diversity of the HIV-1 quasispecies in an infected individual that develops after the initial infection [59-61]. Even during ART suppression of replication, there is a reduced but measurable level of mutation in proviral DNA that contributes to the diversity of HIV-1 genotypes within each individual [62]. Ongoing genotypic variation not only 


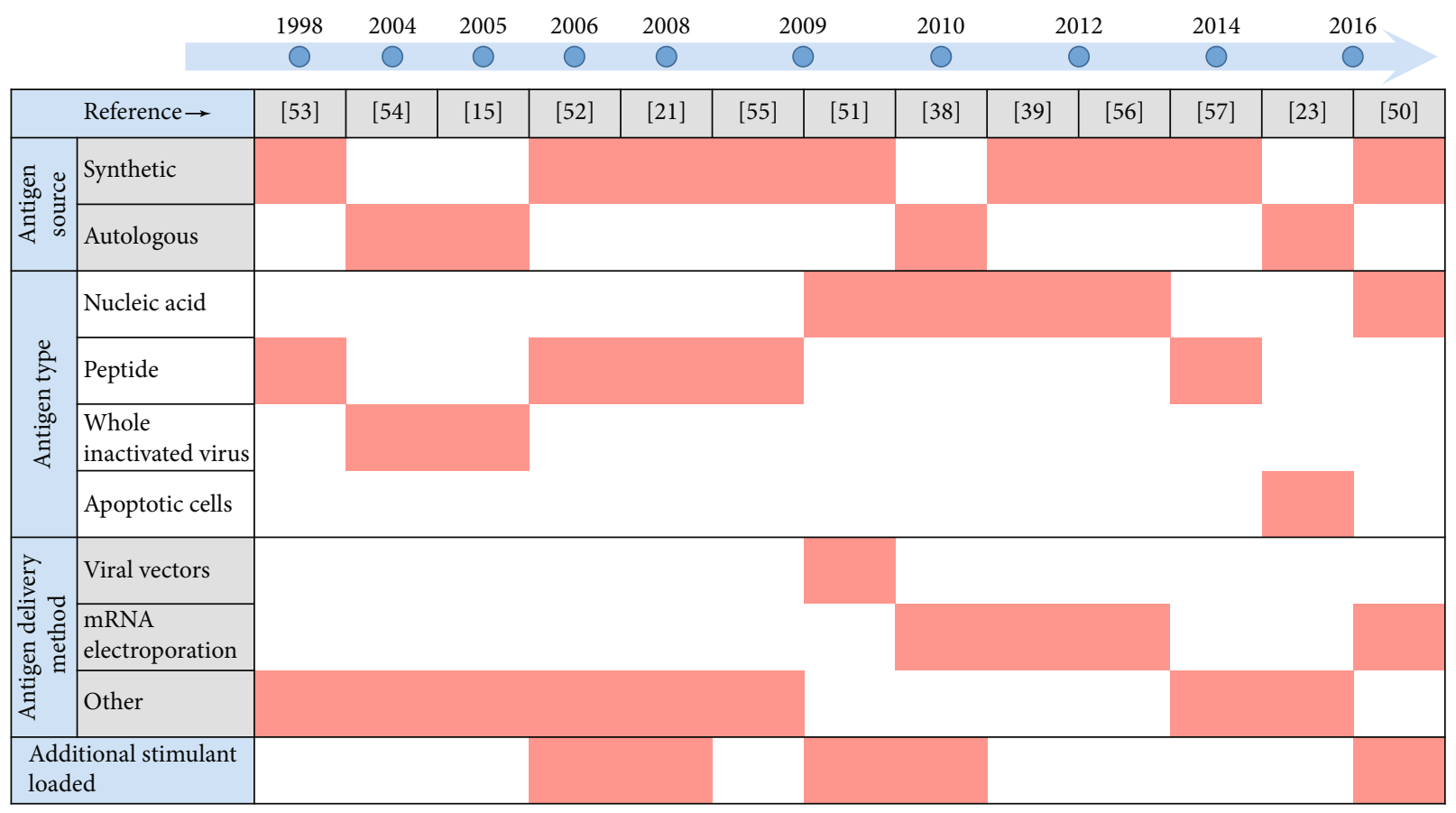

FIgURE 2: Timeline of the DC vaccine formulation design of the first clinical trials done for different studies. The DC vaccine design in these studies $[15,21,23,38,39,50-57]$ varied greatly in antigen type and method of delivery to DCs. More recent clinical trials predominantly investigated DC vaccines electroporated with HIV-1 mRNA. The inclusion of additional immunogens in an effort to maximize efficacy of DC function has been common.

makes immunotherapy more challenging by altering the targets of therapy but also alters the spectrum of HIV-1associated pathogenesis. Studies have uncovered mutations in genes encoding HIV-1 proteins, such as Tat and Vpr, that can be considered determinants and/or markers for altered HIV-1 pathogenic outcomes [63-68]. Minimizing the emergence of HIV-1 quasispecies during the course of infection has been recognized as an important objective of an effective dendritic cell immunotherapy. In addition, clinical trials vary in assays and endpoints used to measure clinical outcomes.

3.1. Patient Selection Criteria. In all clinical trials, the outcome of the trial can be influenced by the inclusion and exclusion criteria that govern patient recruitment into the trial. In the last ten years, even clinical trials which shared the common vaccine formulation design of DCs electroporated with HIV-1 mRNA have varied greatly in experimental setup and reporting of patient information (Table 1). One of the more important parameters for screening eligible patients for DC immunotherapy trials appears to be HIV-1 plasma viral load (generally $<50$ copies $/ \mathrm{mL}$ ) at the beginning of trial before vaccine administration. There has, however, been some variation on what has been considered "low" viremia upon entry into the trial; some studies instead reference residual viremia as being between 1 and 10 copies/mL [6972]. This is further complicated by the need for maintaining stable suppression of viral load in recruited patients on ART alone. The likelihood of treatment failure (i.e., an inability to reduce viral load below the 50 copies $/ \mathrm{mL}$ threshold) increases in patients with increased baseline viral loads $(>150,000$ copies/mL) at ART initiation [16]. In any case, the level of viremia at the start of DC immunotherapy may have an impact on the effectiveness of viral suppression subsequent to DC vaccination. Moreover, an association between the copy number and risk of viral rebound after treatment has been reported [73-75]. The absence of a consensus among different studies regarding the starting viremia in patients selected for trials likely complicates any comparative conclusions about viral rebound after DC vaccination in these trials.

Another variable in patient selection for clinical trials of DC vaccination is the patient's ability to control HIV-1 infection in the absence of ART. Many DC trials investigated efficacy in well-suppressed patients on ART. Without suppressive ART, however, $70-80 \%$ of HIV-1-infected patients progress to the Acquired Immune Deficiency Syndrome (AIDS) after a period of clinical latency [76, 77]. The rate of progression in these patients can vary and can sometimes be rapid. There are, however, smaller numbers of HIV-1-infected individuals known as long-term nonprogressors, or elite controllers, who are able to control infection in the absence of ART $[78,79]$. It has been unclear how much the therapeutic outcome would differ between a long-term nonprogressor who has the ability to maintain normal $\mathrm{CD} 4^{+}$counts and low viremia without ART and individuals who are rapid progressors and developed AIDS much faster in the absence of ART. The remaining HIV-1-infected individuals falling outside this group included rapid progressors or elite controllers [76, 78-80].

Although the outcomes which considered measures of efficacy have differed in recent studies, induction of specific cytokines and antigen-specific T-lymphocyte responses were common endpoints. The ELISPOT (enzyme-linked 


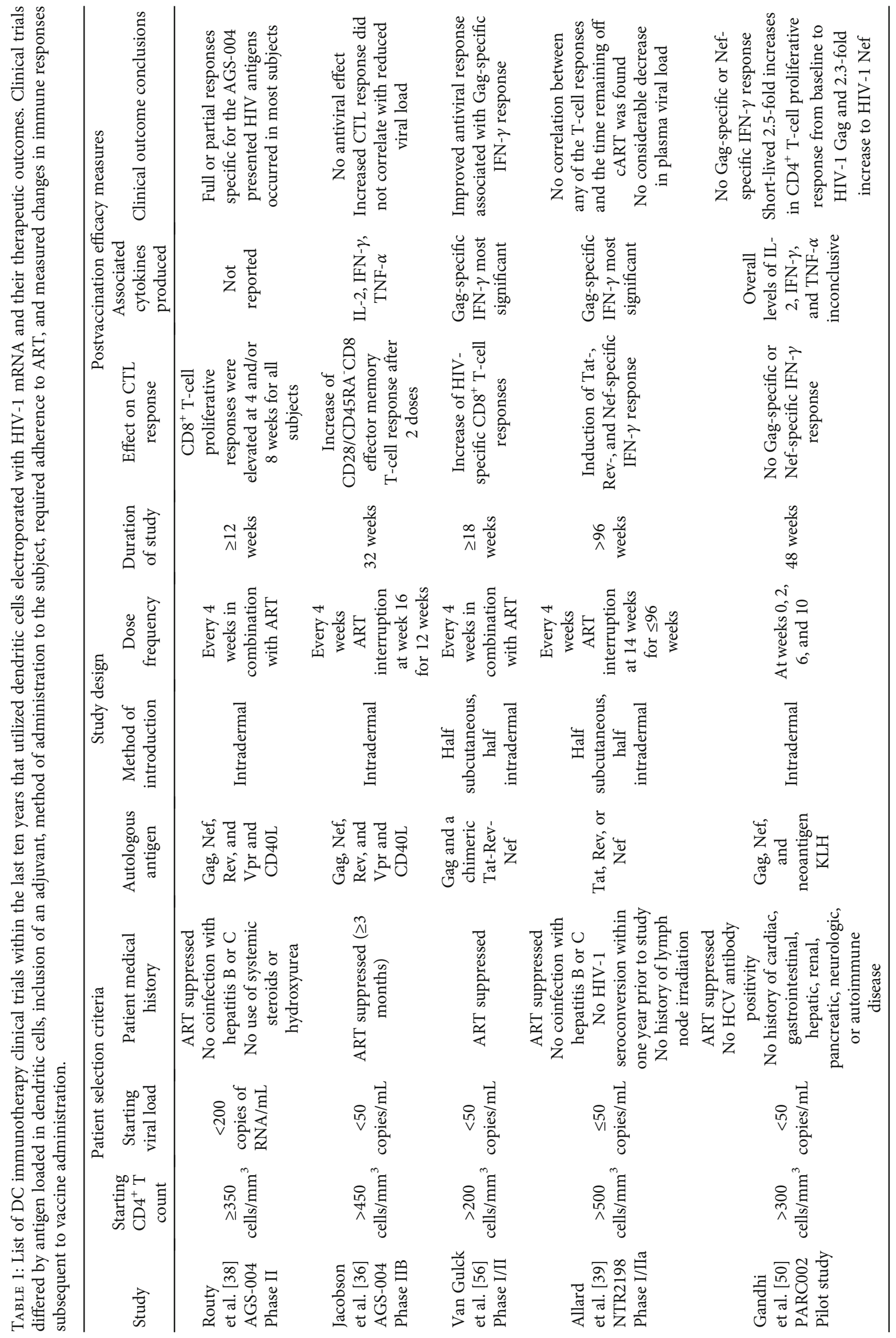


immunosorbent spot) was used to indirectly assess the HIV-1 antigen-specific $\mathrm{CD}^{+} \mathrm{T}$-lymphocyte response through the detection of granzyme B and IFN- $\gamma$ release $[38,81,82]$. Additional outcomes included measurements of T-cell proliferation, changes in $\mathrm{CD} 4^{+} \mathrm{T}$-lymphocyte count, and changes in peripheral blood viral load postvaccination, the latter to specifically check for viral reemergence.

3.2. Conduct and Outcomes of Recent Clinical Trials. A number of clinical trials have been conducted to evaluate the safety and efficacy of DC vaccination strategies. Outcomes of these trials suggested the potential and revealed the limitations of DC-based vaccinations against HIV-1. In addition, these trials highlighted important variables that must be considered in these types of clinical trials, including the impact of genotypic HIV-1 variation (viral quasispecies) on the vaccine effectiveness and the role of ART in determining postvaccination outcomes.

The AGS-004 investigational vaccine reached phase II clinical trials. In this vaccine, RNA encoding consensus sequences from Gag, Nef, Rev, and Vpr were electroporated into patient-derived dendritic cells along with CD40L mRNA [56]. Patients selected for the study were adherent to an ART regimen for at least three months prior to the beginning of the trial. They remained on ART and were administered the AGS-004 vaccine intradermally every four weeks for a total of four treatments. The results specifically showed an increase in $\mathrm{CD}^{+} \mathrm{T}$-lymphocyte proliferative responses in seven of the nine subjects examined. This result was expected, as this vaccine approach was aimed at inducing an effective CTL response to eliminate infection.

A follow-up phase IIB study by Jacobson and colleagues was also completed with the AGS-004 vaccine candidate [36]. In this study, ART discontinuation in all subjects occurred 16 weeks after vaccine administration. The viral kinetics were more closely examined in this study. Unexpectedly, the kinetics appeared to be the same between the subject and placebo groups, suggesting that treatment did not prominently promote an antiviral effect oriented toward limiting viral replication or production. Similar to what was observed in the previous clinical study, however, induction of an HIV1-specific effector memory $\mathrm{CD}^{+} \mathrm{T}$-lymphocyte response occurred in patients who remained on ART. This response was further enhanced by additional treatments with the DC vaccine and was independent of the reemergence of virus with the discontinuation of ART [36].

The influence of variations in quasispecies between individuals on these suboptimal responses was addressed in a later modified study, AGS-004-003, in which patient selection criteria were limited to individuals who initiated ART suppression during acute HIV-1 infection (AHI) [83]. Patients in this study were administered the AGS-004 vaccine monthly, and generation of multifunctional effector $\mathrm{CD}^{+} \mathrm{T}$-cell subtypes was analyzed after 3-4 doses. In these patients, expansion of multifunctional CD28-/CCR7/CD45RA- effector CTLs producing TNF- $\alpha$, IL-12, and IFN- $\gamma$ occurred, at which point the patients underwent analytical treatment interruption. Although vaccine administration did not prevent long-term viral rebound, the expansion of these multifunctional CTLs strongly correlated with a longer time before viral rebound [83]. Additionally, patients in which time to viral rebound was the longest had differentiated effector CTL as opposed to central/memory CTLs, further suggesting that promotion of this transition in the CTL population may serve as an additional measure of efficacy. The results from this most recent trial with AGS-004 vaccination did not support the hypothesis that AGS-004induced HIV-1 control would be more likely in patients suppressed during AHI but nonetheless verified the ability of ex vivo manipulated DCs to promote more robust CTL responses [83].

A similar trial with a Tat-Rev-Nef-Gag mRNA combination electroporated into DCs was performed on six individuals [56]. This study involved a subcutaneous injection of the vaccine along with the intradermal injections every four weeks and continued ART administration postvaccination. In this study, a vaccine-dependent induction of $\mathrm{CD}^{+} \mathrm{T}$ lymphocyte cell effector responses was noted rather than a memory T-cell response. An increase in IFN- $\gamma$ was observed only in response to the Gag antigen [56]. In light of these and other studies, the value of ART continuation or interruption postvaccination is not clear.

Interestingly, different results were produced by a slightly different study that involved ART discontinuation and use of HIV-1 lipopeptides covering epitopes from Gag, Nef, and Pol instead of antigens encoded by RNA. Both a $\mathrm{CD} 4^{+}$and $\mathrm{CD} 8^{+}$ T-lymphocyte expansion was observed in all study participants, as well as prominent IL- 2 and IFN- $\gamma$ production by the $\mathrm{CD} 4^{+} \mathrm{T}$-lymphocyte-specific response [59]. The contribution of $\mathrm{CD}^{+}{ }^{+} \mathrm{T}$-cells to the maintenance of an effective CTL response may thus have been overlooked in many DC vaccine clinical trials. Differences in outcomes between this trial and others may be attributed to differences in the forms of the antigens (particularly Nef- or Pol-derived peptides) as they may be more immunogenic [57]. Additionally, this study documented more detailed information about the patient population and noted that none of the subjects in the study had protective HLA (either B27 or B57) haplotypes, as these may contribute to efficiency of the antigen presentation underlying the desired immune response that was mounted. Furthermore, the study highlighted the need for continued ART, since the subjects that had ART discontinued during the vaccine treatment had a viral load much higher than the treated group that remained on ART [57]. As with the follow-up study on the AGS-004 vaccine, the reasons for the lack of success in controlling viremia in this clinical trial have just begun to be explored. A later study further characterized the importance of the $\mathrm{CD} 4^{+}$T-lymphocyte function in immunized patients following ART discontinuation and found a strong correlation between IL-2- and IL-13producing $\mathrm{CD}^{+}$T-lymphocytes with lower viral loads in patients following ART discontinuation [84]. A further understanding of $\mathrm{CD} 4^{+} \mathrm{T}$-cell function after immunization, in addition to CTL function, may help identify additional means for overcoming the inability to affect sustained control of viremia.

Among these studies, a dendritic cell vaccine was generally considered safe, with the most severe effects reported 
being flu-like symptoms and reactions at the injection site. The concern for autoimmunity was also not observed [38]. In fact, dendritic cell vaccines have been investigated for the treatment of autoimmune diseases [57, 85-88]. In the trials with HIV-1-infected individuals, the slight differences in patient criteria, such as the starting $\mathrm{CD} 4^{+} \mathrm{T}$-cell count and site of injection, may have contributed to the variation in efficacy and may provide insights into the interdependent nature of the immune cells participating in host immune system response. This also highlights the need for other methods of ensuring proper delivery, which would inform the optimal choice of the route of injection. For example, Routy and colleagues [38] argued that intradermal administration would induce better migration through the lymph node relative to subcutaneous delivery. However, the study designs will likely be optimized through the performance of additional clinical trials. While viremia was not shown to be inhibited nor reduced in most trials, the enhancement of the CTL response may greatly help in preventing viral reemergence when combined with other drugs that specifically inhibit HIV-1 replication. The results of these recent studies ultimately highlight the challenge of eradicating HIV-1 using only one approach but suggest that DC vaccination may be a valuable part of a regimen that includes multiple therapeutic approaches.

\section{Considerations for Optimizing DC Vaccines in Future Studies}

The success rate of recent HIV-1 dendritic cell immunotherapy trials has been estimated to be no more than $38 \%$ as determined through a meta-analysis study [89]. Sustaining the induction of HIV-1-specific T-lymphocyte responses elicited by dendritic cell vaccines can be achieved through improvement not only of the design of autologous dendritic cells carrying HIV-1 antigens but also through understanding ways to avoid interfering signaling cascades initiated by other immune cells after delivery to the patient. For this reason, studies have examined the contributions of immunosuppressive $T_{\text {reg }}$ cells with respect to reducing efficacy. These regulatory T-lymphocytes have primarily been of concern because they can either be naturally occurring or develop from naïve T-cells after interaction with dendritic cells and antigen [90-93]. Additionally, patient-specific variables, such as host genetics, need to be considered in determining the mechanisms driving the different results observed in these trials [94]. In a trial with inactivated HIV-1 loaded as a DC-based vaccine, a genetic screening of the subjects revealed polymorphisms in particular genes associated with the immune response (such as the MBL2 gene that is involved in immune recognition) in the subjects experiencing a weak response to the DC vaccine $[54,95]$. In another study, a polymorphism in the CCR4-NOT transcription complex, subunit 1 (CNOT1) gene, was associated with an ineffective response, which may possibly be due to an indirect influence on the expression of genes involved in the inflammatory process [54, 94-96]. Such differences between patients are worthy of further investigation in order to obtain a more accurate prediction of vaccine efficacy in a patient group.

Potential strategies to enhance DC vaccine design include the incorporation of adjuvants as well as specific T-cell immunogens and other molecules that promote the necessary surface ligand interactions to overcome inefficient antigen presentation to $\mathrm{CD}^{+}$T-lymphocytes. A previous strategy for circumventing anticipated challenges in obtaining the desired immunogenicity was the use of the influenza A matrix protein as an adjuvant $[19,97]$. Additional adjuvants, including adenosine deaminase (ADA), have contributed to both $\mathrm{CD}^{+}$and $\mathrm{CD}^{+}$T-cell proliferations after costimulatory molecule expression in dendritic cells [98, 99]. Similarly, an adjuvant combination of CD40L, CD70, and the constitutively active TLR4 (caTLR4) receptor (TRIMIX) was electroporated with HIV-1 antigens into dendritic cells in another study and was shown to cause enhanced IFN$\gamma$ secretion and an increase in HIV-1-specific CTLs after intranodal immunization in mice [100-103].

As many of the most recent studies have focused on mRNA electroporation as opposed to vector carriers, it appears this method of antigen loading has been highly reliable for delivering antigen to DCs. However, other delivery methods not yet examined may provide improved outcomes. Dendrimers as carriers of antigen have been proposed as a delivery method that will facilitate a more controlled antigen release mechanism, resulting in a more efficient response against HIV-1-infected cells [104]. The structure of a dendrimer, which consists of highly branched molecules extending from a core containing cavities and an amine group-rich surface, permits these macromolecules to act as nanocarriers in two ways: through attachment of a drug of choice onto the surface or encapsulating a drug in the internal cavities. Dendrimers have the advantages of low manufacturing costs and scalable synthesis [105]. Alternatively, a polylactic acid colloidal (PLA) nanoparticle was used for the delivery of p24 antigen to myeloid DCs (MD-DCs), which resulted in induction of DC maturation and increases in IFN- $\gamma$ and IL-2 release and migration capacity. The same study also demonstrated that the use of nanoparticles for antigen delivery resulted in an increase in the proliferation of HIV-1-specific CTLs [106].

DC vaccination efficacy may also be enhanced by the administration of immunomodulatory therapies. Treatment with heterodimeric IL-15 (hetIL-15) was used recently to decrease HIV-1 RNA in the plasma, possibly through the maintenance of natural killer (NK) cells. Specifically, hetIL-15 allows for CTL targeting of infected cells in immune privileged sites within the secondary lymphoid tissues [107]. Aside from a suboptimal efficacy, however, some effects of this treatment included the induction of anti-inflammatory processes with an increase in IL-10 production and increased expression of programmed death-1 (PD-1) [108]. Furthermore, PD-1 has been suggested to contribute to HIV-1 disease progression and latent infection through a variety of mechanisms, including the upregulation of the master transcription factor BATF that has been associated with T-cell dysfunction $[109,110]$. Inhibition of this immune checkpoint marker may greatly 
avoid failure associated with T-cell dysfunction in immunotherapy trials.

As many cancers also exhibit efficient evasion of immune recognition, it is possible that more successes can be achieved by applying lessons learned from cancer research. For example, the PD-1 inhibitors, nivolumab and pembrolizumab, have been investigated in cancer research because of their ability to boost the immune response. Both inhibitors have also been tested in HIV-1-infected individuals with cancer [111-113]. Since PD-1 has been considered an immune checkpoint or coinhibitory molecule, its inhibition of Tlymphocytes has been shown to allow for tumor or infected cell eradication by preventing the T-lymphocyte exhaustion that occurs due to overexposure to antigen [114-116]. Alternatively, a mechanism suggested to be the cause of success during DC vaccine administration in cancers is immunogenic cell death (ICD). Display of damage-associated molecular patterns (DAMPs), such as calreticulin, induces engulfment when bound by the CD91 receptor on phagocytes such as dendritic cells $[111,116]$. The induction of DAMP expression by various stimuli has been suggested to enhance DC vaccines directed against certain cancers, as it promotes DC maturation and subsequent activation of CTLs specific to tumor cells $[114,117-120]$. This process, if it can be applied as part of a viral therapeutic strategy, may enhance the efficacy of HIV-1-specific DC therapeutic vaccines.

\section{Maximizing HIV-1 DC Immunotherapy Using Combinatorial Approaches to Overcome Latency}

Immunotherapy and control of HIV-1 reemergence postvaccination represent a lower degree of difficulty relative to the more challenging goal of achieving complete eradication of the virus in HIV-1-infected individuals [121]. The replication cycle of HIV-1 is a relatively challenging target for chemotherapeutic approaches that may be proposed as the basis of a functional cure within the near future. ART alone is impractical as a means of eradication, as it has been estimated that over 60 years of ART would be necessary to completely eradicate infected cells from the body $[122,123]$.

Perhaps, one of the central elements associated with achieving the goal of HIV-1 eradication is the issue of latent infection and the necessity of reactivating and/or eliminating the latently infected, persistent cell reservoir. While immunotherapy could be used to promote immune responses against productively infected cells, cells harboring latent HIV-1 proviral DNA are much more challenging targets since they express few or no viral proteins. In addition, factors that contribute to latency may be outside the scope of immunotherapeutic approaches. For example, variations in the HIV-1 long terminal repeat (LTR), which are associated with clinical disease severity and might also be linked to the maintenance of viral latency [124], would not be addressed by an ex vivo DC vaccination approach, since the LTR does not code for proteins that could be targeted by immunotherapy. As one approach to overcome these challenges, $\mathrm{DC}$ vaccines may need to be combined with latency reversing agents (LRAs) to allow for more effective purging of the viral reservoirs. Interestingly, the inability of many $\mathrm{DC}$ vaccine trials to achieve a reduced HIV-1 RNA load after vaccination may be due to either an increase in virus production caused by the vaccine or killing of infected cells by the CTLs [23].

Immunomodulatory drugs such as thalidomide and pomalidomide can potentially increase the chances of reversing latency when utilized with dendritic cell vaccines. These drugs were found to enhance the lytic activity of HIV-1specific CTLs as well as acting on the humoral branch of the immune system to reactivate Epstein-Barr Virus (EBV) in resting memory $B$ cells $[125,126]$. Latency reversal reagents such as the histone deacetylase inhibitor (HDACi) vorinostat can rapidly cause a change in gene expression that results in the induction of HIV-1 gene transcription in the resting $\mathrm{CD}^{+}$memory T-lymphocyte reservoir [127-130]. Additionally, the HIV-1 accessory protein Tat has been found to contribute greatly to the reactivation of latent infection. When Tat is present, the HDAC inhibitors vorinostat and panobinostat as well as the bromodomain inhibitor JQ1 can further increase HIV-1 gene transcription [131, 132]. While this was demonstrated for these drugs when used individually, it is important to note that multiple LRAs may need to be used in combination as they are unlikely to be efficient in vivo when used individually [133]. However, it remains to be determined if LRAs would still need to be used in combination with a dendritic cell vaccine against HIV-1. In conclusion, there appear to be multiple avenues for combination strategies designed to either enhance control of HIV-1 infection or lead to a cure for HIV-1 infection through complete eradication of the virus (Figure 3 ).

\section{Conclusions}

The dendritic cell immunotherapy approach may still be a promising method of immunotherapy targeted at increasing the efficacy of an individual's own immune response against HIV-1 infection. By allowing for the manipulation of autologous antigen-presenting cells in various ways, this approach has the potential advantages of reversing the antigen presentation dysfunctions observed in HIV-1-infected individuals as well as achieving stimulation of both $\mathrm{CD} 4^{+}$and $\mathrm{CD} 8^{+} \mathrm{T}$ cell responses. Because of these advantages, DC immunotherapy has the potential to be used for long-term control of HIV-1 infection or even complete eradication of HIV-1 from infected individuals. One of the primary challenges in eradicating HIV-1 infection appears to be establishing longterm control of viral replication while simultaneously eliminating the viral reservoirs and preventing viral reemergence due to escape mutations. The multitude of effects elicited, unlike other therapies that rely on a specific mechanism of HIV-1 inhibition (such as entry inhibition), provides DC vaccines with the potential to provide a more long-term therapeutic effect, even if that effect is ART-free control of HIV-1 infection (a "functional cure") rather than eradication. Additionally, their safety profiles allow them to be readily used as possible synergistic or supplementary therapies with other approaches to provide maximal protection against HIV-1 disease progression or virus eradication. 


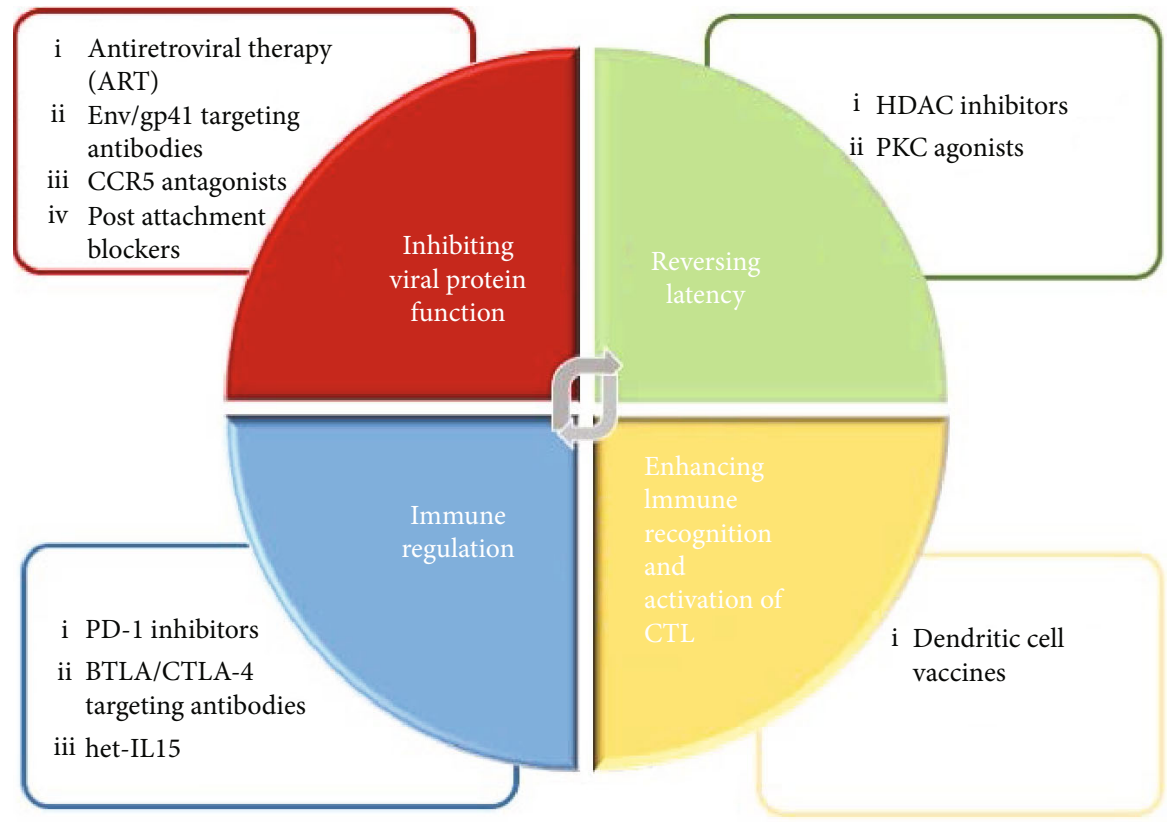

FIgURE 3: Summary of strategies currently being investigated for HIV-1 treatment. The design of a long-term HIV-1 treatment is generally focused on four approaches; reversing latency, inhibiting T-cell exhaustion markers, inhibiting viral protein function, and enhancing HIV-1 antigen recognition and immune regulation. Dendritic cell immunotherapy in the form of DC vaccines allows for a more unique approach to treating HIV-1 infection by specifically inducing better recognition by and activation of CTLs. Other therapies for HIV-1 infection can be combined to compensate for shortcomings of a single treatment option to provide optimal control of HIV-1 disease progression, viral resistance, and the spread of infection.

However, the varying levels of effectiveness reported among the different DC vaccination trials over the last ten years suggest a need to standardize measures of efficacy in order to better understand the potential of the DC vaccine to induce long-term immune protection and viral control in the absence of ART. Accordingly, standardization of patient selection criteria along with consistent and thorough reporting of patient background would simultaneously determine possible host influences on achieving long-term viral suppression. After additional trials focusing on the optimized administration of autologous cells carrying various forms and combinations of HIV-1 antigens, HIV-1-specific DC immunotherapy has the potential not only to offer ARTfree control of HIV-1 infection but also to be a part of future eradication strategies that merit further investigation and development.

\section{Conflicts of Interest}

The authors declare that there is no conflict of interest regarding the publication of this literature review.

\section{Acknowledgments}

Preparation and publication costs associated with this review were defrayed by the faculty development funds provided by the Department of Microbiology and Immunology and the Institute for Molecular Medicine and Infectious Disease in the College of Medicine Drexel University. BW is supported by the Public Health Service, National Institutes of Health, through grants from the (1) National Institute of Mental Health (NIMH) (R01 MH110360) (Contact PI, BW) and (2) NIMH Comprehensive NeuroAIDS Center (CNAC) (P30 MH092177) (Kamel Khalili, PI; Brian Wigdahl, PI; of the Drexel subcontract involving the Clinical and Translational Research Support Core).

\section{References}

[1] A. R. Hersperger, J. N. Martin, L. Y. Shin et al., "Increased HIV-specific $\mathrm{CD}^{+}$T-cell cytotoxic potential in HIV elite controllers is associated with T-bet expression," Blood, vol. 117, no. 14, pp. 3799-3808, 2011.

[2] A. Saez-Cirion, C. Lacabaratz, O. Lambotte et al., "HIV controllers exhibit potent CD8 T cell capacity to suppress HIV infection ex vivo and peculiar cytotoxic T lymphocyte activation phenotype," Proceedings of the National Academy of Sciences, vol. 104, no. 16, pp. 6776-6781, 2007.

[3] C. Alvarez-Dominguez, R. Calderon-Gonzalez, H. TeranNavarro et al., "Dendritic cell therapy in melanoma," Annals of Translational Medicine, vol. 5, no. 19, p. 386, 2017.

[4] R. O. Dillman, S. R. Selvan, P. M. Schiltz et al., "Phase II trial of dendritic cells loaded with antigens from self-renewing, proliferating autologous tumor cells as patient-specific antitumor vaccines in patients with metastatic melanoma: final report," Cancer Biotherapy and Radiopharmaceuticals, vol. 24, no. 3, pp. 311-319, 2009.

[5] E. M. Inderberg Suso, S. Dueland, A.-M. Rasmussen et al., "hTERT mRNA dendritic cell vaccination: complete response in a pancreatic cancer patient associated with 
response against several hTERT epitopes," Cancer Immunology, Immunotherapy, vol. 60, no. 6, pp. 809-818, 2011.

[6] F. Granucci, I. Zanoni, S. Feau, and P. Ricciardi-Castagnoli, "Dendritic cell regulation of immune responses: a new role for interleukin 2 at the intersection of innate and adaptive immunity," The EMBO Journal, vol. 22, no. 11, pp. 25462551, 2003.

[7] C. Hamimi, A. David, P. Versmisse et al., "Dendritic Cells from HIV Controllers Have Low Susceptibility to HIV-1 Infection In Vitro but High Capacity to Capture HIV-1 Particles," PLoS One, vol. 11, no. 8, article e0160251, 2016.

[8] J. Dinter, E. Duong, N. Y. Lai et al., "Variable processing and cross-presentation of HIV by dendritic cells and macrophages shapes CTL immunodominance and immune escape," PLoS Pathogens, vol. 11, no. 3, article e1004725, 2015.

[9] X.-. L. Huang, Z. Fan, L. Zheng et al., "Priming of human immunodeficiency virus type 1 (HIV-1)-specific $\mathrm{CD} 8^{+} \mathrm{T}$ cell responses by dendritic cells loaded with HIV-1 proteins," The Journal of Infectious Diseases, vol. 187, no. 2, pp. 315319, 2003.

[10] J. Mait-Kaufman, E. Fakioglu, P. M. M. Mesquita, J. Elliott, Y. Lo, and R. P. Madan, "Chronic HIV infection is associated with upregulation of proinflammatory cytokine and chemokine and alpha defensin gene expression in colorectal mucosa," AIDS Research and Human Retroviruses, vol. 31, no. 6, pp. 615-622, 2015.

[11] A. Moris, A. Pajot, F. Blanchet, F. Guivel-Benhassine, M. Salcedo, and O. Schwartz, "Dendritic cells and HIVspecific $\mathrm{CD}^{+} \mathrm{T}$ cells: HIV antigen presentation, T-cell activation, and viral transfer," Blood, vol. 108, no. 5, pp. 16431651, 2006.

[12] J. Chehimi, D. E. Campbell, L. Azzoni et al., "Persistent decreases in blood plasmacytoid dendritic cell number and function despite effective highly active antiretroviral therapy and increased blood myeloid dendritic cells in HIV-infected individuals," Journal of Immunology, vol. 168, no. 9, pp. 4796-4801, 2002.

[13] H. Donaghy, A. Pozniak, B. Gazzard et al., "Loss of blood $\mathrm{CD}_{11 \mathrm{c}^{+}}$myeloid and CD11c plasmacytoid dendritic cells in patients with HIV-1 infection correlates with HIV-1 RNA virus load," Blood, vol. 98, no. 8, pp. 2574-2576, 2001.

[14] J. Fontaine, F. Coutlée, C. Tremblay et al., "HIV infection affects blood myeloid dendritic cells after successful therapy and despite nonprogressing clinical disease," The Journal of Infectious Diseases, vol. 199, no. 7, pp. 1007-1018, 2009.

[15] F. Garcia, M. Lejeune, N. Climent et al., "Therapeutic immunization with dendritic cells loaded with heat-inactivated autologous HIV-1 in patients with chronic HIV-1 infection," The Journal of Infectious Diseases, vol. 191, no. 10, pp. 16801685, 2005.

[16] V. Pirrone, D. J. Libon, C. Sell, C. A. Lerner, M. R. Nonnemacher, and B. Wigdahl, "Impact of age on markers of HIV-1 disease," Future Virology, vol. 8, no. 1, pp. 81-101, 2013.

[17] M. D. Hazenberg, D. Hamann, H. Schuitemaker, and F. Miedema, "T cell depletion in HIV-1 infection: how $\mathrm{CD} 4^{+} \mathrm{T}$ cells go out of stock," Nature Immunology, vol. 1, no. 4, pp. 285-289, 2000.

[18] D. Corti, J. P. M. Langedijk, A. Hinz et al., "Analysis of memory B cell responses and isolation of novel monoclonal antibodies with neutralizing breadth from HIV-1-infected individuals," PLoS One, vol. 5, no. 1, p. e8805, 2010.
[19] R. Pejchal, K. J. Doores, L. M. Walker et al., "A potent and broad neutralizing antibody recognizes and penetrates the HIV glycan shield," Science, vol. 334 , no. 6059, pp. 10971103, 2011.

[20] L. M. Walker, M. Huber, K. J. Doores et al., "Broad neutralization coverage of HIV by multiple highly potent antibodies," Nature, vol. 477, no. 7365, pp. 466-470, 2011.

[21] N. C. Connolly, T. L. Whiteside, C. Wilson, V. Kondragunta, C. R. Rinaldo, and S. A. Riddler, "Therapeutic immunization with human immunodeficiency virus type 1 (HIV-1) peptideloaded dendritic cells is safe and induces immunogenicity in HIV-1-infected individuals," Clinical and Vaccine Immunology, vol. 15, no. 2, pp. 284-292, 2008.

[22] F. García, N. Climent, L. Assoumou et al., "A therapeutic dendritic cell-based vaccine for HIV-1 infection,” The Journal of Infectious Diseases, vol. 203, no. 4, pp. 473-478, 2011.

[23] B. J. C. Macatangay, S. A. Riddler, N. D. Wheeler et al., "Therapeutic vaccination with dendritic cells loaded with autologous HIV type 1-infected apoptotic cells," The Journal of Infectious Diseases, vol. 213, no. 9, pp. 1400-1409, 2016.

[24] L. Min, S. A. B. M. Isa, W. N. Fam et al., "Synergism between curdlan and GM-CSF confers a strong inflammatory signature to dendritic cells," Journal of Immunology, vol. 188, no. 4, pp. 1789-1798, 2012.

[25] L. van de Laar, P. J. Coffer, and A. M. Woltman, "Regulation of dendritic cell development by GM-CSF: molecular control and implications for immune homeostasis and therapy," Blood, vol. 119, no. 15, pp. 3383-3393, 2012.

[26] T. L. Whiteside, P. Piazza, A. Reiter et al., "Production of a dendritic cell-based vaccine containing inactivated autologous virus for therapy of patients with chronic human immunodeficiency virus type 1 infection," Clinical and Vaccine Immunology, vol. 16, no. 2, pp. 233-240, 2009.

[27] S. Shah, M. R. Nonnemacher, V. Pirrone, and B. Wigdahl, "Innate and adaptive factors regulating human immunodeficiency virus type 1 genomic activation," Journal of Neuroimmune Pharmacology, vol. 5, no. 3, pp. 278-293, 2010.

[28] T. Ikeda, M. Symeonides, J. S. Albin, M. Li, M. Thali, and R. S. Harris, "HIV-1 adaptation studies reveal a novel Envmediated homeostasis mechanism for evading lethal hypermutation by APOBEC3G," PLOS Pathogens, vol. 14, no. 4, article e1007010, 2018.

[29] O. Manches, D. Frleta, and N. Bhardwaj, "Dendritic cells in progression and pathology of HIV infection," Trends in Immunology, vol. 35, no. 3, pp. 114-122, 2014.

[30] E. Clark, B. Nava, and M. Caputi, "Tat is a multifunctional viral protein that modulates cellular gene expression and functions," Oncotarget, vol. 8, no. 16, pp. 27569-27581, 2017.

[31] P. Mlcochova, L. Apolonia, S. F. Kluge et al., "Immune evasion activities of accessory proteins $\mathrm{Vpu}, \mathrm{Nef}$ and Vif are conserved in acute and chronic HIV-1 infection," Virology, vol. 482, pp. 72-78, 2015.

[32] A. Seelamgari, A. Maddukuri, R. Berro et al., "Role of viral regulatory and accessory proteins in HIV-1 replication," Frontiers in Bioscience, vol. 9, no. 1-3, pp. 2388-2413, 2004.

[33] A. T. Das, A. Harwig, and B. Berkhout, "The HIV-1 Tat protein has a versatile role in activating viral transcription," Journal of Virology, vol. 85, no. 18, pp. 9506-9516, 2011.

[34] S. Richter, I. Frasson, and G. Palu, "Strategies for inhibiting function of HIV-1 accessory proteins: a necessary route to 
AIDS therapy?," Current Medicinal Chemistry, vol. 16, no. 3, pp. 267-286, 2009.

[35] L. Niu, J. M. Termini, S. K. Kanagavelu et al., "Preclinical evaluation of HIV-1 therapeutic ex vivo dendritic cell vaccines expressing consensus Gag antigens and conserved Gag epitopes," Vaccine, vol. 29, no. 11, pp. 2110-2119, 2011.

[36] J. M. Jacobson, J. P. Routy, S. Welles et al., "Dendritic cell immunotherapy for HIV-1 infection using autologous HIV1 RNA: a randomized, double-blind, placebo-controlled clinical trial," Journal of Acquired Immune Deficiency Syndromes, vol. 72, no. 1, pp. 31-38, 2016.

[37] M. Altfeld, M. M. Addo, R. Shankarappa et al., "Enhanced detection of human immunodeficiency virus type 1-specific $\mathrm{T}$-cell responses to highly variable regions by using peptides based on autologous virus sequences," Journal of Virology, vol. 77, no. 13, pp. 7330-7340, 2003.

[38] J. P. Routy, M. R. Boulassel, B. Yassine-Diab et al., "Immunologic activity and safety of autologous HIV RNAelectroporated dendritic cells in HIV-1 infected patients receiving antiretroviral therapy," Clinical Immunology, vol. 134, no. 2, pp. 140-147, 2010.

[39] S. D. Allard, B. De Keersmaecker, A. L. de Goede et al., "A phase I/IIa immunotherapy trial of HIV-1-infected patients with Tat, Rev and Nef expressing dendritic cells followed by treatment interruption," Clinical Immunology, vol. 142, no. 3, pp. 252-268, 2012.

[40] T. D. Norton, E. A. Miller, N. Bhardwaj, and N. R. Landau, "Vpx-containing dendritic cell vaccine induces CTLs and reactivates latent HIV-1 in vitro," Gene Therapy, vol. 22, no. 3, pp. 227-236, 2015.

[41] E. G. Wee, B. Ondondo, P. Berglund et al., "HIV-1 Conserved Mosaics Delivered by Regimens with Integration-Deficient DC- Targeting Lentiviral Vector Induce Robust T Cells," Molecular Therapy, vol. 25, no. 2, pp. 494-503, 2017.

[42] K. N. Smith, R. B. Mailliard, B. B. Larsen et al., "Dendritic cells restore CD8+ T cell reactivity to autologous HIV-1," Journal of Virology, vol. 88, no. 17, pp. 9976-9990, 2014.

[43] K. Brown, W. Gao, S. Alber et al., "Adenovirus-transduced dendritic cells injected into skin or lymph node prime potent simian immunodeficiency virus-specific $\mathrm{T}$ cell immunity in monkeys," Journal of Immunology, vol. 171, no. 12, pp. 6875-6882, 2003.

[44] M. F. Pascutti, A. M. Rodriguez, J. Falivene, L. Giavedoni, I. Drexler, and M. M. Gherardi, "Interplay between modified vaccinia virus Ankara and dendritic cells: phenotypic and functional maturation of bystander dendritic cells," Journal of Virology, vol. 85, no. 11, pp. 5532-5545, 2011.

[45] P. H. Tan, S. C. Beutelspacher, S.-A. Xue et al., "Modulation of human dendritic-cell function following transduction with viral vectors: implications for gene therapy," Blood, vol. 105, no. 10, pp. 3824-3832, 2005.

[46] C. Faurie, M. Golzio, E. Phez, J. Teissie, and M. P. Rols, "Electric field-induced cell membrane permeabilization and gene transfer: theory and experiments," Engineering in Life Sciences, vol. 5, no. 2, pp. 179-186, 2005.

[47] Y. Guo, Y. Zhang, G. M. Nijm et al., "Irreversible electroporation in the liver: contrast-enhanced inversion-recovery MR imaging approaches to differentiate reversibly electroporated penumbra from irreversibly electroporated ablation zones," Radiology, vol. 258, no. 2, pp. 461-468, 2011.
[48] J. C. Weaver and Y. A. Chizmadzhev, "Theory of electroporation: a review," Bioelectrochemistry and Bioenergetics, vol. 41, no. 2, pp. 135-160, 1996.

[49] Y. Zhao, Z. Zheng, C. J. Cohen et al., "High-efficiency transfection of primary human and mouse T lymphocytes using RNA electroporation," Molecular Therapy, vol. 13, no. 1, pp. 151-159, 2006.

[50] R. T. Gandhi, D. S. Kwon, E. A. Macklin et al., "Immunization of HIV-1-infected persons with autologous dendritic cells transfected with mRNA encoding HIV-1 Gag and Nef: results of a randomized, placebo-controlled clinical trial," Journal of Acquired Immune Deficiency Syndromes, vol. 71, no. 3, pp. 246-253, 2016.

[51] R. T. Gandhi, D. O’Neill, R. J. Bosch et al., “A randomized therapeutic vaccine trial of canarypox-HIV-pulsed dendritic cells vs. canarypox-HIV alone in HIV-1-infected patients on antiretroviral therapy," Vaccine, vol. 27, no. 43, pp. 6088-6094, 2009.

[52] F. Ide, T. Nakamura, M. Tomizawa et al., "Peptide-loaded dendritic-cell vaccination followed by treatment interruption for chronic HIV-1 infection: a phase 1 trial," Journal of Medical Virology, vol. 78, no. 6, pp. 711-718, 2006.

[53] S. K. Kundu, E. Engleman, C. Benike et al., "A pilot clinical trial of HIV antigen-pulsed allogeneic and autologous dendritic cell therapy in HIV-infected patients," AIDS Research and Human Retroviruses, vol. 14, no. 7, pp. 551-560, 1998.

[54] W. Lu, L. C. Arraes, W. T. Ferreira, and J. M. Andrieu, "Therapeutic dendritic-cell vaccine for chronic HIV-1 infection," Nature Medicine, vol. 10, no. 12, pp. 1359-1365, 2004.

[55] H. Kloverpris, I. Karlsson, J. Bonde et al., "Induction of novel $\mathrm{CD}^{+}$T-cell responses during chronic untreated HIV-1 infection by immunization with subdominant cytotoxic Tlymphocyte epitopes," AIDS, vol. 23, no. 11, pp. 1329-1340, 2009.

[56] E. Van Gulck, E. Vlieghe, M. Vekemans et al., "mRNA-based dendritic cell vaccination induces potent antiviral T-cell responses in HIV-1-infected patients," AIDS, vol. 26, no. 4, pp. F1-12, 2012.

[57] Y. Levy, R. Thiebaut, M. Montes et al., "Dendritic cell-based therapeutic vaccine elicits polyfunctional HIV-specific Tcell immunity associated with control of viral load," European Journal of Immunology, vol. 44, no. 9, pp. 2802-2810, 2014.

[58] J. Zheng, Q. Liu, J. Yang et al., "Co-culture of apoptotic breast cancer cells with immature dendritic cells: a novel approach for DC-based vaccination in breast cancer," Brazilian Journal of Medical and Biological Research, vol. 45, no. 6, pp. 510515, 2012.

[59] S. Danaviah, T. de Oliveira, M. Gordon et al., "Analysis of dominant HIV quasispecies suggests independent viral evolution within spinal granulomas coinfected with mycobacterium tuberculosis and HIV-1 subtype C," AIDS Research and Human Retroviruses, vol. 32, no. 3, pp. 262-270, 2016.

[60] C. Hedskog, M. Mild, J. Jernberg et al., "Dynamics of HIV-1 quasispecies during antiviral treatment dissected using ultra-deep pyrosequencing," PLoS One, vol. 5, no. 7, article e11345, 2010.

[61] ICONA Foundation Group, "Evolution of HIV-1 tropism at quasispecies level after 5 years of combination antiretroviral therapy in patients always suppressed or experiencing episodes of virological failure," The Journal of Antimicrobial Chemotherapy, vol. 69, no. 11, pp. 3085-3094, 2014. 
[62] W. Dampier, M. R. Nonnemacher, J. Mell et al., "HIV-1 genetic variation resulting in the development of new quasispecies continues to be encountered in the peripheral blood of well-suppressed patients," PLoS One, vol. 11, no. 5, article e0155382, 2016.

[63] C. Spector, A. R. Mele, B. Wigdahl, and M. R. Nonnemacher, "Genetic variation and function of the HIV-1 Tat protein," Medical Microbiology and Immunology, vol. 208, no. 2, pp. 131-169, 2019.

[64] W. Dampier, G. C. Antell, B. Aiamkitsumrit et al., "Specific amino acids in HIV-1 Vpr are significantly associated with differences in patient neurocognitive status," Journal of Neurovirology, vol. 23, no. 1, pp. 113-124, 2017.

[65] R. W. Link, A. R. Mele, G. C. Antell et al., "Investigating the distribution of HIV-1 Tat lengths present in the Drexel Medicine CARES cohort," Virus Research, vol. 272, p. 197727, 2019.

[66] S. Dahiya, B. P. Irish, M. R. Nonnemacher, and B. Wigdahl, "Genetic variation and HIV-associated neurologic disease," Advances in Virus Research, vol. 87, pp. 183-240, 2013.

[67] G. C. Antell, W. Dampier, B. Aiamkitsumrit et al., "Evidence of divergent amino acid usage in comparative analyses of R5and X4-associated HIV-1 Vpr sequences," International Journal of Genomics, vol. 2017, 4081511 pages, 2017.

[68] B. Aiamkitsumrit, W. Dampier, G. Antell et al., "Bioinformatic analysis of HIV-1 entry and pathogenesis," Current HIV Research, vol. 12, no. 2, pp. 132-161, 2014.

[69] C. Charpentier, R. Landman, C. Laouenan et al., "Persistent low-level HIV-1 RNA between 20 and 50 copies/mL in antiretroviral-treated patients: associated factors and virological outcome," The Journal of Antimicrobial Chemotherapy, vol. 67, no. 9, pp. 2231-2235, 2012.

[70] T. W. Chun, J. S. Justement, D. Murray et al., "Rebound of plasma viremia following cessation of antiretroviral therapy despite profoundly low levels of HIV reservoir: implications for eradication," AIDS, vol. 24, no. 18, pp. 2803-2808, 2010.

[71] E. Helou, S. Shenoi, T. Kyriakides, M. L. Landry, M. Kozal, and L. A. Barakat, "Characterizing patients with very-lowlevel HIV viremia: a community-based study," Journal of the International Association of Providers of AIDS Care (JIAPAC), vol. 16, no. 3, pp. 261-266, 2016.

[72] F. Maggiolo, A. Callegaro, G. Cologni et al., "Ultrasensitive assessment of residual low-level HIV viremia in HAARTtreated patients and risk of virological failure," Journal of Acquired Immune Deficiency Syndromes, vol. 60, no. 5, pp. 473-482, 2012.

[73] T. Doyle, C. Smith, P. Vitiello et al., "Plasma HIV-1 RNA detection below 50 copies/ml and risk of virologic rebound in patients receiving highly active antiretroviral therapy," Clinical Infectious Diseases, vol. 54, no. 5, pp. 724-732, 2012.

[74] P. Ryscavage, S. Kelly, J. Z. Li, P. R. Harrigan, and B. Taiwo, "Significance and clinical management of persistent lowlevel viremia and very-low-level viremia in HIV-1-infected patients," Antimicrobial Agents and Chemotherapy, vol. 58, no. 7, pp. 3585-3598, 2014.

[75] L. Sarmati, G. D'Ettorre, S. Parisi, and M. Andreoni, "HIV replication at low copy number and its correlation with the HIV reservoir: a clinical perspective," Current HIV Research, vol. 13, no. 3, pp. 250-257, 2015.

[76] S. Limou, S. Le Clerc, C. Coulonges et al., "Genomewide association study of an AIDS-nonprogression cohort emphasizes the role played by HLA genes (ANRS Genomewide Association Study 02)," The Journal of Infectious Diseases, vol. 199, no. 3, pp. 419-426, 2009.

[77] G. Sharma, G. Kaur, and N. Mehra, "Genetic correlates influencing immunopathogenesis of HIV infection," The Indian Journal of Medical Research, vol. 134, no. 6, pp. 749768, 2011.

[78] S. Grabar, H. Selinger-Leneman, S. Abgrall, G. Pialoux, L. Weiss, and D. Costagliola, "Prevalence and comparative characteristics of long-term nonprogressors and HIV controller patients in the French hospital database on HIV," AIDS, vol. 23, no. 9, pp. 1163-1169, 2009.

[79] P. W. Hunt, "Natural control of HIV-1 replication and longterm nonprogression: overlapping but distinct phenotypes," The Journal of Infectious Diseases, vol. 200, no. 11, pp. 1636-1638, 2009.

[80] C. Casado, S. Colombo, A. Rauch et al., "Host and viral genetic correlates of clinical definitions of HIV-1 disease progression," PLoS One, vol. 5, no. 6, article e11079, 2010.

[81] M. Slota, J. B. Lim, Y. Dang, and M. L. Disis, "ELISpot for measuring human immune responses to vaccines," Expert Review of Vaccines, vol. 10, no. 3, pp. 299-306, 2014.

[82] H. Streeck, N. Frahm, and B. D. Walker, "The role of IFN- $\gamma$ Elispot assay in HIV vaccine research," Nature Protocols, vol. 4, no. 4, pp. 461-469, 2009.

[83] C. L. Gay, M. A. DeBenedette, I. Y. Tcherepanova et al., "Immunogenicity of AGS-004 dendritic cell therapy in patients treated during acute HIV infection," AIDS Research and Human Retroviruses, vol. 34, no. 1, pp. 111-122, 2018.

[84] M. Surenaud, M. Montes, C. S. Lindestam Arlehamn et al., "Anti-HIV potency of T-cell responses elicited by dendritic cell therapeutic vaccination," PLOS Pathogens, vol. 15, no. 9, article e1008011, 2019.

[85] P. Garcia-Gonzalez, G. Ubilla-Olguin, D. Catalan, K. Schinnerling, and J. C. Aguillon, "Tolerogenic dendritic cells for reprogramming of lymphocyte responses in autoimmune diseases," Autoimmunity Reviews, vol. 15, no. 11, pp. 1071-1080, 2016.

[86] R. A. Harry, A. E. Anderson, J. D. Isaacs, and C. M. U. Hilkens, "Generation and characterisation of therapeutic tolerogenic dendritic cells for rheumatoid arthritis," Annals of the Rheumatic Diseases, vol. 69, no. 11, pp. 2042-2050, 2010.

[87] M. Y. Mok, "Tolerogenic dendritic cells: role and therapeutic implications in systemic lupus erythematosus," International Journal of Rheumatic Diseases, vol. 18, no. 2, pp. 250-259, 2015.

[88] I. Van Brussel, W. P. Lee, M. Rombouts et al., "Tolerogenic dendritic cell vaccines to treat autoimmune diseases: can the unattainable dream turn into reality?," Autoimmunity Reviews, vol. 13, no. 2, pp. 138-150, 2014.

[89] Y. Zhou, X. Leng, S. Luo et al., "Tolerogenic dendritic cells generated with tofacitinib ameliorate experimental autoimmune encephalomyelitis through modulation of Th17/Treg balance," Journal of Immunology Research, vol. 2016, Article ID 5021537, 13 pages, 2016.

[90] A. Coelho, R. de Moura, A. Kamada et al., "Dendritic cellbased immunotherapies to fight HIV: how far from a success story? A systematic review and meta-analysis," International Journal of Molecular Sciences, vol. 17, no. 12, p. $1985,2016$. 
[91] S. Li, E. J. Gowans, C. Chougnet, M. Plebanski, and U. Dittmer, "Natural regulatory T cells and persistent viral infection," Journal of Virology, vol. 82, no. 1, pp. 21-30, 2008.

[92] A. M. Sanchez and Y. Yang, "The role of natural regulatory T cells in infection," Immunologic Research, vol. 49, no. 1-3, pp. 124-134, 2011.

[93] S. Andre, D. F. Tough, S. Lacroix-Desmazes, S. V. Kaveri, and J. Bayry, "Surveillance of Antigen-Presenting Cells by $\mathrm{CD}^{+-}$ CD25+ Regulatory T Cells in Autoimmunity: Immunopathogenesis and Therapeutic Implications," The American Journal of Pathology, vol. 174, no. 5, pp. 1575-1587, 2009.

[94] B. J. Macatangay and C. R. Rinaldo, "Regulatory T cells in HIV immunotherapy," HIV Therapy, vol. 4, no. 6, pp. 639647, 2010.

[95] R. Moura, A. Pontillo, P. D'Adamo, N. Pirastu, A. C. Coelho, and S. Crovella, "Exome analysis of HIV patients submitted to dendritic cells therapeutic vaccine reveals an association of CNOT1 gene with response to the treatment," Journal of the International AIDS Society, vol. 17, no. 1, p. 18938, 2014.

[96] A. Pontillo, R. C. Da Silva, R. Moura, and S. Crovella, "Host genomic HIV restriction factors modulate the response to dendritic cell-based treatment against HIV-1," Human Vaccines \& Immunotherapeutics, vol. 10, no. 2, pp. 512-518, 2014.

[97] M. R. Fabian, F. Frank, C. Rouya et al., "Structural basis for the recruitment of the human CCR4-NOT deadenylase complex by tristetraprolin," Nature Structural \& Molecular Biology, vol. 20, no. 6, pp. 735-739, 2013.

[98] S. E. Magnusson, A. F. Altenburg, K. L. Bengtsson et al., "Matrix-M adjuvant enhances immunogenicity of both protein- and modified vaccinia virus Ankara-based influenza vaccines in mice," Immunologic Research, vol. 66, no. 2, pp. 224-233, 2018.

[99] P. Yu, J. C. Steel, M. Zhang, J. C. Morris, and T. A. Waldmann, "Simultaneous blockade of multiple immune system inhibitory checkpoints enhances antitumor activity mediated by interleukin-15 in a murine metastatic colon carcinoma model," Clinical Cancer Research, vol. 16, no. 24, pp. 60196028, 2010.

[100] A. Bonehill, S. Tuyaerts, A. M. Van Nuffel et al., "Enhancing the T-cell Stimulatory Capacity of Human Dendritic Cells by Co- electroporation With CD40L, CD70 and Constitutively Active TLR4 Encoding mRNA," Molecular Therapy, vol. 16, no. 6, pp. 1170-1180, 2008.

[101] A. C. Guardo, P. T. Joe, L. Miralles et al., "Preclinical evaluation of an mRNA HIV vaccine combining rationally selected antigenic sequences and adjuvant signals (HTI-TriMix)," AIDS, vol. 31, no. 3, pp. 321-332, 2017.

[102] M. Iwabuchi, M. Narita, T. Uchiyama et al., "Enhancement of the antigen-specific cytotoxic T lymphocyte-inducing ability in the PMDC11 leukemic plasmacytoid dendritic cell line via lentiviral vector-mediated transduction of the caTLR4 gene," Molecular Medicine Reports, vol. 12, no. 2, pp. 2443-2450, 2015.

[103] J. M. Martinez-Navio, V. Casanova, R. Pacheco et al., “Adenosine deaminase potentiates the generation of effector, memory, and regulatory $\mathrm{CD}^{+}{ }^{+} \mathrm{T}$ cells," Journal of Leukocyte Biology, vol. 89, no. 1, pp. 127-136, 2011.

[104] M. Takahashi, M. Iwabuchi, N. Satoh et al., "Potentiation of antigen-specific CTL generation by caTLR4 gene transduction into leukemic plasmacytoid dendritic cell line (PMDC11) (APP3P.108)," Journal of Immunology, vol. 192, no. 1, Supplement, p. 111.9, 2014.
[105] M. M. Angeles Munoz-Fernandez, F. J. de la Mata, M. Pion, E. Vacas-Cordoba, M. Galan, and R. Gomez, "Enhanced activity of carbosilane dendrimers against HIV when combined with reverse transcriptase inhibitor drugs: searching for more potent microbicides," International Journal of Nanomedicine, vol. 9, pp. 3591-3600, 2014.

[106] D. Sepulveda-Crespo, J. L. Jimenez, R. Gomez et al., "Polyanionic carbosilane dendrimers prevent hepatitis $\mathrm{C}$ virus infection in cell culture," Nanomedicine, vol. 13, no. 1, pp. 49-58, 2017.

[107] N. Climent, S. Munier, N. Pique et al., "Loading dendritic cells with PLA-p24 nanoparticles or MVA expressing HIV genes induces HIV-1-specific T cell responses," Vaccine, vol. 32, no. 47, pp. 6266-6276, 2014.

[108] D. C. Watson, E. Moysi, A. Valentin et al., "Treatment with native heterodimeric IL-15 increases cytotoxic lymphocytes and reduces SHIV RNA in lymph nodes," PLOS Pathogens, vol. 14, no. 2, article e1006902, 2018.

[109] F. Porichis and D. E. Kaufmann, "Role of PD-1 in HIV pathogenesis and as target for therapy," Current HIV/AIDS Reports, vol. 9, no. 1, pp. 81-90, 2012.

[110] M. Quigley, F. Pereyra, B. Nilsson et al., "Transcriptional analysis of $\mathrm{HIV}$-specific $\mathrm{CD}^{+} \mathrm{T}$ cells shows that PD-1 inhibits T cell function by upregulating BATF," Nature Medicine, vol. 16, no. 10, pp. 1147-1151, 2010.

[111] G. J. Freeman, E. J. Wherry, R. Ahmed, and A. H. Sharpe, "Reinvigorating exhausted HIV-specific T cells via PD-1PD-1 ligand blockade," The Journal of Experimental Medicine, vol. 203, no. 10, pp. 2223-2227, 2006.

[112] L. Ostios-Garcia, J. Faig, G. C. Leonardi et al., "Safety and Efficacy of PD-1 Inhibitors Among HIV-Positive Patients With Non-Small Cell Lung Cancer," Journal of Thoracic Oncology, vol. 13, no. 7, pp. 1037-1042, 2018.

[113] R. Sundar, B. C. Cho, J. R. Brahmer, and R. A. Soo, "Nivolumab in NSCLC: latest evidence and clinical potential," Therapeutic Advances in Medical Oncology, vol. 7, no. 2, pp. 8596, 2015.

[114] M. de Bruyn, V. R. Wiersma, W. Helfrich, P. Eggleton, and E. Bremer, "The ever-expanding immunomodulatory role of calreticulin in cancer immunity," Frontiers in Oncology, vol. 5, p. 35, 2015.

[115] S. J. Gardai, K. A. McPhillips, S. C. Frasch et al., "Cell-surface calreticulin initiates clearance of viable or apoptotic cells through trans-activation of LRP on the phagocyte," Cell, vol. 123, no. 2, pp. 321-334, 2005.

[116] V. Velu, R. D. Shetty, M. Larsson, and E. M. Shankar, "Role of PD-1 co-inhibitory pathway in HIV infection and potential therapeutic options," Retrovirology, vol. 12, no. 1, p. 14, 2015.

[117] O. Kepp, L. Senovilla, and G. Kroemer, "Immunogenic cell death inducers as anticancer agents," Oncotarget, vol. 5, no. 14, pp. 5190-5191, 2014.

[118] A. Showalter, A. Limaye, J. L. Oyer et al., "Cytokines in immunogenic cell death: applications for cancer immunotherapy," Cytokine, vol. 97, pp. 123-132, 2017.

[119] R. Wang, T. Town, V. Gokarn, R. A. Flavell, and R. Y. Chandawarkar, "HSP70 Enhances hagocytosis by Interaction With Lipid Raft- Associated TLR-7 and Upregulating p38 MAPK and PI3K Pathways," The Journal of Surgical Research, vol. 136, no. 1, pp. 58-69, 2006.

[120] T. Yamano, S. Kubo, M. Fukumoto et al., "Whole cell vaccination using immunogenic cell death by an oncolytic 
adenovirus is effective against a colorectal cancer model," Molecular Therapy - Oncolytics, vol. 3, p. 16031, 2016.

[121] P. K. Datta, R. Kaminski, W. Hu et al., "HIV-1 latency and eradication: past, present and future," Current HIV Research, vol. 14, no. 5, pp. 431-441, 2016.

[122] D. Finzi, J. Blankson, J. D. Siliciano et al., "Latent infection of $\mathrm{CD} 4^{+} \mathrm{T}$ cells provides a mechanism for lifelong persistence of HIV-1, even in patients on effective combination therapy," Nature Medicine, vol. 5, no. 5, pp. 512-517, 1999.

[123] A. Alexaki, Y. Liu, and B. Wigdahl, "Cellular reservoirs of HIV-1 and their role in viral persistence," Current HIV Research, vol. 6, no. 5, pp. 388-400, 2008.

[124] M. R. Nonnemacher, V. Pirrone, R. Feng et al., "HIV-1 promoter single nucleotide polymorphisms are associated with clinical disease severity," PLoS One, vol. 11, no. 4, article e0150835, 2016.

[125] B. De Keersmaecker, S. D. Allard, P. Lacor, R. Schots, K. Thielemans, and J. L. Aerts, "Expansion of polyfunctional HIV-specific T cells upon stimulation with mRNA electroporated dendritic cells in the presence of immunomodulatory drugs," Journal of Virology, vol. 86, no. 17, pp. 9351-9360, 2012.

[126] R. J. Jones, T. Iempridee, X. Wang et al., "Lenalidomide, thalidomide, and pomalidomide reactivate the Epstein-Barr virus lytic cycle through phosphoinositide 3-kinase signaling and Ikaros expression," Clinical Cancer Research, vol. 22, no. 19, pp. 4901-4912, 2016.

[127] N. M. Archin, R. Bateson, M. K. Tripathy et al., "HIV-1 expression within resting $\mathrm{CD} 4{ }^{+} \mathrm{T}$ cells after multiple doses of vorinostat," The Journal of Infectious Diseases, vol. 210, no. 5, pp. 728-735, 2014.

[128] J. H. Elliott, F. Wightman, A. Solomon et al., "Activation of HIV transcription with short-course vorinostat in HIVinfected patients on suppressive antiretroviral therapy," PLoS Pathogens, vol. 10, no. 11, article e1004473, 2014.

[129] M. B. Lucera, C. A. Tilton, H. Mao et al., "The histone deacetylase inhibitor vorinostat (SAHA) increases the susceptibility of uninfected $\mathrm{CD} 4^{+} \mathrm{T}$ cells to HIV by increasing the kinetics and efficiency of postentry viral events," Journal of Virology, vol. 88, no. 18, pp. 10803-10812, 2014.

[130] D. G. Wei, V. Chiang, E. Fyne et al., "Histone deacetylase inhibitor romidepsin induces HIV expression in CD4 T cells from patients on suppressive antiretroviral therapy at concentrations achieved by clinical dosing," PLoS Pathogens, vol. 10, no. 4, article e1004071, 2014.

[131] C. Banerjee, N. Archin, D. Michaels et al., "BET bromodomain inhibition as a novel strategy for reactivation of HIV1," Journal of Leukocyte Biology, vol. 92, no. 6, pp. 1147$1154,2012$.

[132] G. Khoury, T. M. Mota, S. Li et al., "HIV latency reversing agents act through Tat post translational modifications," Retrovirology, vol. 15, no. 1, p. 36, 2018.

[133] V. Gupta and N. M. Dixit, "Trade-off between synergy and efficacy in combinations of HIV-1 latency-reversing agents," PLOS Computational Biology, vol. 14, no. 2, article e1006004, 2018. 